\title{
EL PAPEL DE LA AD- M-19 COMO \\ FUERZA POLÍtICA ALTERNATIVA EN LA CONSTITUYENTE DE $1991^{1}$
}

Jose David Moreno Mancera ${ }^{2}$

THE ROLE OF THE AD-M-19 AS AN ALTERNATIVE POLITICAL

FORCE DURING THE 1991 CONSTITUTIONAL ASSEMBLY

O PAPEL DA AD-M-19 COMO FORÇA POLÍTICA

ALTERNATIVA NA CONSTITUIÇÃO DE 1991

Fecha de recepción: 24 de noviembre del 2020

Fecha de aceptación: $1 .^{\circ}$ de marzo del 2021

Disponible en línea: 26 de abril del 2021

\section{Sugerencia de citación:}

Moreno Mancera, J. D. (2021). El papel de la AD- M-19 como fuerza política alternativa en la Constituyente de 1991. Razón Crítica, (11), 33-64. https://doi.org/10.21789/25007807.1742

(1) El presente artículo se estructura a partir de la tesis titulada: De las balas a los votos: acuerdo de paz, tránsito a la vida civil y trayectoria política de la Alianza Democrática M-19 (1989-1998), presentada para obtener el título de doctor en Historia de la Universidad Nacional de Colombia. El profesor universitario Aguilera Peña, del Instituto de Estudios Políticos y Relaciones Internacionales, dirigió esa investigación.

(2) Historiador de la Universidad Nacional y administrador público de la Escuela Superior de Administración Pública, con estudios de maestría en historia moderna y relaciones internacionales de Universidad de Lyon. Estudios de doctorado en Ciencia Política, Instituto Europeo de Posgrado, Aix-en-Provence. Estudiante del Doctorado en Historia de la Universidad Nacional de Colombia, Colombia |jdmorenom@yahoo.com.ar | https://orcid.org/0000-0003-0513-1205 


\section{R E S U M E N}

Este artículo busca describir, desde una perspectiva histórica, las dinámicas que tuvieron lugar entre 1990 y 1991 no solo en el desarrollo de la Asamblea Nacional Constituyente, sino especialmente en una de sus bancadas más importantes: la Alianza Democrática M-19. Esto resulta relevante, ya que esta organización política era nueva para la época en la arena electoral; a pesar de ello tuvo un respaldo electoral muy importante. Este escrito ofrece una mirada enfocada tanto en los miembros de la bancada, de forma particular, como de la organización política, de forma general. El análisis toma relevancia si se tiene en cuenta que en muy pocos años la Alianza Democrática M-19 desapareció como organización política; sin embargo, su aporte a la institucionalidad colombiana sigue vigente. Las ideas que se exponen a continuación son fruto de una investigación que se basó especialmente en entrevistas a los protagonistas implicados, así como archivos personales de algunos miembros de la Alianza Democrática de esa época.

PALA BRAS CLAVE: Alianza Democrática M-19;

Asamblea Nacional Constituyente; sistema político colombiano; partidos políticos alternativos. 


\section{A B S T R A C T}

This paper describes, from a historical perspective, the dynamics that took place between 1990 and 1991 during the National Constituent Assembly, with a particular emphasis on one of the most important political parties involved: the M-19 Democratic Alliance. This is relevant considering that although it was a new political organization in the electoral scenery at that time, this party received strong support from voters. This writing provides an outlook on both the members of this party, in particular, and the political organization, in general. The analysis gains importance when taking into account that the $\mathrm{M}-19$ Democratic Alliance disappeared as a political organization years later. Despite this, its contribution to Colombian institutions remains until these days. The ideas presented below are the result of a research study based on interviews with key actors involved, as well as personal files of some members of the Democratic Alliance from that time.

Keywords: M-19 Democratic Alliance; National

Constituent Assembly; Colombian political system; alternative political parties.

\section{R E S U M O}

Neste artigo, busca-se descrever, de uma perspectiva histórica, as dinâmicas que aconteceram entre 1990 e 1991 não somente no desenvolvimento da Assembleia Nacional Constituinte, mas especialmente numa de suas bancadas mais importantes: a Aliança Democrática M-19. Isso resulta relevante, já que essa organização política era nova para a época na arena eleitoral; apesar disso, teve um apoio eleitoral muito importante. Neste texto, é oferecida uma visão focada tanto nos membros da bancada, de forma particular, quanto da organização política, de forma geral. A análise ganha relevância se for considerado que, em poucos anos, a Aliança Democrática M-19 desapareceu como organização política; contudo, sua contribuição para a institucionalidade colombiana continua vigente. As ideias que são expostas a seguir são fruto de uma pesquisa que foi baseada especialmente em entrevistas aos protagonistas envolvidos, bem como em arquivos pessoais de alguns membros da Aliança Democrática dessa época.

PALAVRAS-CHAVE: Aliança Democrática M-19;

Assembleia Nacional Constituinte; sistema político colombiano; partidos políticos alternativos. 
El periodo de 27 de mayo (día de las elecciones presidenciales) a 9 de diciembre de 1990 (día de las elecciones a la Asamblea Constituyente) representa una etapa fundamental para la Alianza Democrática M-19 (en adelante, AD), un partido que estaba recién configurado y esperaba plantearse como una alternativa dentro del sistema político colombiano³. En efecto, en la AD confluyen organizaciones y partidos de izquierda que desde finales de los ochenta trataban de consolidar un proyecto unificado ${ }^{4}$. A esto se sumaban los desmovilizados del M-19 que habían entregado las armas el 9 de marzo de 1990 y poseían una gran visibilidad nacional, incluyendo a sus dos grandes líderes, Carlos Pizarro (asesinado el 26 de abril de 1990) y Antonio Navarro (Bula, 2018).

Muchos de los sectores que participaron en la AD venían presionando años atrás para consolidar una asamblea constituyente que reformara de fondo a la institucionalidad colombiana. Por esto, en 1990, la AD abanderó igualmente la iniciativa (Dugas, 1993). En ese año electoral la AD se convirtió en todo un fenómeno mediático y generó un golpe de opinión. Cuando la Asamblea Nacional Constituyente (ANC) se materializó, la AD se movilizó por todo el país para participar en este escenario. En realidad, la participación de la AD en la constituyente representó el esplendor político y electoral de esta organización (Navarro, 2018). Por esto, en este artículo queremos ver, de forma descriptiva, la participación de la AD en la constituyente. Nuestra pregunta de base aquí es: ¿cómo se desarrolló la

3 La creación oficial del partido AD-M-19 fue el 2 de abril de 1990; contó con la presencia de importantes dirigentes sociales, sindicales y de la izquierda colombiana. En las elecciones a la Constituyente la ad ya había participado en tres contiendas electorales.

4 Hacemos referencia especialmente a organizaciones, como el socialismo democrático, atado a sectores sindicales; el Frente Popular, corriente política del Partido Comunista Colombiano Marxista Leninista PCC-ML; los círculos Bernardo Jaramillo, que albergaban los sectores democráticos de la Unión Patriótica, y Colombia Unida, que aglutinaba los sectores y movimientos políticos regionales. 
participación de la bancada de la AD en la ANC? Esto bajo el entendiendo que después del partido liberal, la AD fue la segunda fuerza política más votada. Se considera, a modo de hipótesis, que esto no fue suficiente para imponer a la AD como una fuerza política relevante dentro de los equilibrios del sistema político. En las elecciones del 9 de diciembre no hubo un clientelismo o transacciones entre los partidos tradicionales y el electorado. Esto le abrió entonces el espacio a la AD para imponerse con casi un tercio de los constituyentes dentro de la Asamblea. Los partidos tradicionales no le prestaron una gran atención en un primer momento a esta coyuntura política e institucional, ya que consideraban que podría ser fácilmente manipulada para sus intereses propios (Cepeda, 1993).

Lo que se considera aquí es que la consolidación de la bancada de la AD que participó en la ANC fue altamente plural y tuvo un propósito general representado en la figura de Antonio Navarro. Esta pluralidad no se enfrentó de forma radical con las élites, sino que hizo concesiones a estas, con el fin de tener un espacio más amplio en el sistema político (Patiño, 2018). Para esto, se puede ver cómo, desde lo individual, la bancada se consolidó con una diversa serie de actores que incluso llegaban a ser cercanos a las élites y partidos tradicionales. La AD se mezclaba con otros partidos más radicales que buscaban hacer reformas más de fondo. La bancada contó con actores, que, en algunas ocasiones, vieron en la AD más una oportunidad electoral que un proyecto organizativo con vida propia (Grabe, 2017). En una mirada más de conjunto, la bancada de la AD trabajó en temas de importancia para el país, sin llegar forzosamente a modificar las estructuras sociales y políticas. Al final, de la mano de su líder, obtuvo demasiadas transacciones con el partido de Gobierno, las cuales opacaron la acción de la AD como actor clave dentro de la ANC (Novoa, 2018).

Este artículo se estructura en tres partes centrales. En la primera, se presentan algunos antecedentes históricos de la consolidación de la ANC; la segunda expone la conformación y el análisis de la lista de la AD para la constituyente. La última describe cómo operó y participó la AD en el marco de la redacción de la nueva carta política.

\section{RADIOGRAFÍA DE UNA CONSTITUYENTE}

El lapso que transcurrió entre la elección de César Gaviria como presidente y su posesión (de mayo a agosto de 1990) resultó crucial en 
términos políticos e institucionales para Colombia (Misas, 2002). Hay dos explicaciones para esto. Primero, era evidente el compromiso de este dirigente con una Asamblea Constitucional ${ }^{5}$ para implementar cambios institucionales que el país requería. En segundo lugar, Gaviria, y detrás de él todo el partido liberal ${ }^{6}$, estaba obsesionado por controlar los cambios que esta asamblea propiciara (Gutiérrez, 2007). Una prueba fue no solo el apoyo a que hubiera un temario definido y no una reforma total a la Constitución, sino la instalación de cerca de mil mesas de trabajo preparatorias para la asamblea, que resultaron en 150 mil propuestas. Estas mesas se desarrollaron en alcaldías, gobernaciones y comisarías del país ${ }^{7}$. Sin embargo, el Gobierno nacional controló estas mesas. A pesar de la gran publicidad y recursos desplegados en este ejercicio, el grueso de la sociedad civil no entendió claramente sobre qué trataba la constituyente. Este desconocimiento, combinado con apatía, resultó en una abstención totalmente desalentadora (Pardo, 1996).

El 9 de diciembre de 1990 una parte minoritaria de colombianos votaron. De los más de 13 millones que podrían votar, solo lo hicieron cerca de 3 millones (Holguín, 1991). Hubo una abstención muy alta en estos comicios, que fueron los terceros que se celebraban ese año. Ahora bien, además del aspecto de ser la tercera elección de $1990^{8}$, otros elementos jugaron un papel clave en abstención. Enfatizamos el hecho de que los colombianos nunca, a lo largo del siglo xx, habían votado por una asamblea constituyente. A pesar de todo, existió un profundo

\footnotetext{
5 Vale la pena hacer la aclaración que había un debate significativo para aquella época entre Asamblea Constitucional y Asamblea Constituyente. La primera denotaba básicamente una suerte de reforma a la constitución de 1886 basados en unos temas previamente determinados. Por el contrario, la Asamblea Constituyente planteaba la posibilidad de reformar por completo la constitución de 1886 sin tener que limitarse a temarios previos. Esta fue la alternativa que terminó por imponerse gracias al fallo de la Corte Suprema de Justicia el 9 de octubre de 1990 y que rompió las limitaciones del temario definido. A partir de allí sería una Asamblea Constituyente y no Constitucional.

6 Es destacable en este punto el papel jugado en aquellos meses por Alfonso López Michelsen. Al respecto véase la notable radiografía que hace Francisco Gutiérrez (2007) del Partido Liberal en aquellos años.

$7 \quad$ Como balance de esas mesas de preparación se pudo percibir que en materia de prioridades los colombianos consideraban la paz como el aspecto más importante. Seguido a ello vendrían la educación, la reforma del Congreso y del sistema electoral como elementos fundamentales a tener en cuenta a la hora de reformar la Constitución. Las mesas de trabajo se repartieron en temas como: reforma del congreso, reforma a la justicia, ministerio público, administración pública, derechos humanos, partidos políticos y oposición (que sería coordinada por Gerardo Ardila, antiguo cuadro del M-19), régimen territorial, mecanismos de participación (coordinada por María Teresa Garcés, futura constituyente por la AD-M-19), estado de sitio, control fiscal, y desde luego, aspectos económicos.

8 En 1990 se había realizado elecciones en marzo para Congreso, corporaciones locales y consulta liberal, algunas semanas después, en mayo, se realizaron elecciones presidenciales.
} 
desconocimiento sobre que trataba esa reforma. Sin embargo, por encima de estos factores, estaba el hecho de que en estas elecciones no se movilizaron las fuerzas clientelistas. Este fue un hecho que le abrió el paso a fuerzas diferentes a las tradicionales, liberal y conservadora, como la AD. Dado que en un principio se trataba de una asamblea constitucional con un temario específico, los partidos tradicionales consideraron que las amenazas no eran mayores. No obstante, la Corte Suprema efectuó un fallo el 9 de octubre, el cual le daba un espectro más amplio a la asamblea y la volvía constituyente. Como resultado, los partidos tradicionales se sintieron poco cómodos, dada la confianza inicial de que no habría reformas de fondo (Pabón, 2018). En los dos meses que trascurrieron entre el fallo de la corte y las elecciones a la ANC, tanto liberales como conservadores tuvieron que hacer a marcha forzada los cálculos políticos con el fin de no quedarse por fuera del tren de la constituyente. Así lo registró la prensa de la época:
El Partido Liberal y el Partido Conservador están contra la pared y ninguno sabe qué hacer frente a esta nueva realidad. Como verdaderamente ninguno de los dos creía que se iba a llegar a esta situación, la decisión de la Corte, al dejar sin piso el acuerdo político, los cogió fuera de base. Sin anticipar el fenómeno Navarro, procedieron a diseñar estrategias electorales tradicionales (Semana, 1990).

Dado que no existió una presión clientelista de los grandes barones electorales, Navarro y su lista de la AD siempre estuvieron a la cabeza de las encuestas. Así lo confirman los datos recolectados por el Centro Nacional de Consultoría, que, para finales de octubre de 1990, mostraban a Navarro como el favorito en las intenciones de voto. En Bogotá, Cali y Barranquilla, el líder de la AD lograba superar por más de 20 puntos a Gómez, segundo en las intenciones de voto (Semana, 1990). Esta situación se confirmaba una semana después cuando otra encuesta realizada por $E l$ Tiempo y Caracol mostraba que el ex jefe guerrillero tenía un 45,5\% de las intenciones de voto, es decir, cerca de la mitad (El Tiempo, 1990). Como lo señala Buenahora: "[...] los inconformes de Colombia preferían la opción Navarro, frente a las de Gaviria, Gómez, Pastrana o Lloreda” (Buenahora, 1991, p. 332).

En verdad, la AD recogía el descontento de los colombianos fatigados del esquema bipartidista en un país azotado por una severa crisis institucional. A pesar del éxito de experiencias alternativas en el pasado, y 
a excepción de la Alianza Nacional Popular (Anapo), la AD se convirtió en una verdadera alternativa al bipartidismo de ese momento (Deas, 2019).

Empero, las lecturas convergieron en diversas direcciones. La prensa y la opinión pública interpretaron a esta Alianza como el partido político de la guerrilla del M-19, lo cual era un error porque pese a que cuadros notables de la guerrilla hacían parte del partido, la AD no representaba únicamente a los desmovilizados de la guerrilla. Resulta curioso ver cómo el común de las personas, la prensa e incluso los destacados líderes sociales y políticos no hablaban de la Alianza Democrática M-19, sino simplemente del M-19, lo que dejaba la sensación de ser el partido de esa guerrilla. Otra lectura que se dio en su momento de la AD fue como un partido de izquierda democrática, como esa fuerza alternativa capaz de reemplazar el entusiasmo trágico de la Unión Patriótica u otras experiencias previas (Garzón, 2018).

Sin embargo, ser de izquierda en un país marcado por décadas de conflicto armado resultaba complejo, dado que siempre se asociaban estos sectores tanto con las guerrillas y la lucha armada como con el comunismo internacional. Por esto, resultaba muy fácil asociar la AD con estas tendencias y estereotipos de la época (Villa, 2018). La gran estrategia que se planteaba en general por el partido pero especialmente por parte de Navarro en ese momento era mostrarse como un centro moderado, muy cercano a las tendencias socialdemócratas de aquella época (Irragori, 2004). Esto servía para evitar relacionarse con la insurgencia y el comunismo, lo que permitía penetrar más cómodamente el sistema político colombiano. Alternativamente, servía como una clara posición político-ideológica de algunos líderes de la Alianza ${ }^{9}$.

La AD se alineaba con los deseos de reforma del ambiente político y social. Grandes propuestas, como la reforma al Congreso, la organización territorial, la reforma a la justicia o los órganos de control, no solo estaban en boca de la Alianza, sino en general de la mayoría de grupos políticos que participaban en la contienda.

La prensa de la época hizo una radiografía del entusiasmo que se vivió en aquellos momentos, cuando se calculaba que alrededor de 34 curules en la Asamblea serían para el recién creado partido. Este ascenso

9 Con respecto a este punto nunca hubo un real acuerdo entre los miembros y cuadros de la adM-19. Muchos sectores abogaban por ser claros y ubicarse a la izquierda del espectro político, como un movimiento alternativo, pero otros sectores muy influyentes, bajo la dirección de Navarro, no compartían esa posición, lo que terminó por imponerse. 
espectacular de la AD, al menos en lo mediático, encendió las alarmas de diversos sectores políticos, en especial, de los partidos tradicionales. Congresistas liberales como Horacio Serpa o Jaime Castro dejaron su puesto parlamentario para unirse al tren constituyente y luchar contra la arremetida del M-19. Tanto liberales como conservadores no ahorraron esfuerzos en advertir a los electores que una constitución escrita por exguerrilleros llevaría el país a la hecatombe, al comunismo o al socialismo (Buenahora; 1991), esfuerzo compartido, desde luego, por Álvaro Gómez, líder del Movimientos de Salvación Nacional (MSN) y feroz oponente no solo de la ANC, sino de la AD (Constaín, 2019) ${ }^{10}$. Figuras ortodoxas como Rodrigo Lloreda, Carlos Lemmos o Jaime Castro prevenían con ahínco la demagogia y el populismo que para ellos representaba la AD (Cabarcas, 2011). El electorado aún no comprendía claramente que la Alianza no era el partido político del M-19, que estaba compuesta por diversos sectores sociales, dentro de los cuales el más visible eran los desmovilizados de la guerrilla. Parte de las intrigas que se dieron en contra de la AD se vieron orquestadas desde el mismo Congreso de la República, el cual en la primera semana de noviembre de 1990 abrió un debate sobre los hechos ocurridos en el Palacio de Justicia en el marco del quinto aniversario del holocausto, todavía muy fresco en la memoria de los colombianos. La mala propaganda y la publicidad que le dieron a estos hechos, además de los temores que abrigaban los diversos candidatos de los partidos liberal y conservador terminaron surtiendo el efecto esperado: reducir el número de votos en favor de la AD. La llegada a la ANC de grandes nombres políticos también arrastró un número importante de votos que hubieran podido ser para la AD. Sin embargo, más allá de todas estas circunstancias, el éxito de la AD resultó relativo, ya que captó muchos votos dentro de una considerable minoría que votó en esa jornada. Si bien para el partido fue motivo de euforia, en términos concretos un voto de opinión, más bien urbano y enfocado en ciertas regiones le dio el triunfo a la AD. No era la expresión de una nación que votaba por un cambio de fondo, sino la expresión de sectores independientes que apoyaban una propuesta relativamente novedosa.

10 Baste con ver la entrevista que me concedió Gómez a El Tiempo, que fue publicada el día de las elecciones a la anc: "ET: ¿Cree que con el triunfo del M-19 en la Constituyente, peligra el futuro político del país? AG: Por supuesto que sí. No sabemos cómo se van a portar y los del M-19 son de violencia, [...] son gentes amnistiadas que delinquieron"(El Tiempo, 1990, 4A). 


\section{LA AD-M-19 EN LA ASAMBLEA NACIONAL CONSTITUYENTE. RETOS EN LA CONFIGURACIÓN POLÍTICA DE LA ORGANIZACIÓN}

Entonces, se enfilaron baterías y calentaron motores para consolidar la lista con la cual la AD se presentaría a las elecciones para una Asamblea Nacional Constituyente. Queremos enfatizar la construcción de listas. Este hecho se convirtió en sujeto de intenso debate, de pugnas internas y de tensiones (Pineda, 2018). Resulta totalmente apasionante, desde el punto de vista académico, ver todo el intercambio epistolar entre los grandes dirigentes de la AD, especialmente, los que sostuvo Navarro con los más diversos sectores nacionales del partido. Estas cartas ponían en evidencia cómo los más amplios sectores reclamaban un pedazo del "feudo" político para ser incluidos en las listas (Archivo Fucude, 1990). Muchas de las cartas resaltaban que la cantidad de votos recibidos por Navarro durante los comicios presidenciales de mayo debían reflejarse en la lista de candidatos a la constituyente. Gremios de gran importancia, como los educadores, le hacieron saber también a Navarro que su espacio estaba ganado en una futura lista. A su vez, de forma progresiva, Navarro, para ese momento ministro de Salud, determinó quiénes iban en la lista y en

qué orden. En el círculo de los antiguos miembros de la AD se conoció este hecho como el poder del bolígrafo. Este poder hizo a Navarro el amo y señor de los destinos políticos del partido (Patiño, 2018).

Vale la pena reflexionar sobre la lista que se presentó a la Asamblea Nacional Constituyente en nombre de la AD. Para el segundo semestre de 1990 era claro que una de las doctrinas de las cuales partía la Alianza era la de la inclusión de los más diversos sectores. Se intentó respetar tal vez el espíritu que había impregnado Carlos Pizarro. Esta situación fue ampliamente debatida y, a su vez, motivo de resentimientos. Se consideraba que se le estaban dando demasiadas concesiones a los partidos y sectores tradicionales, que se desdibujaba el espíritu de alternatividad y de oposición, que este partido debería tener. 
Tabla 1. Lista $n .^{\circ} 9$ a la Asamblea Nacional Constituyente de la AD-M-19

\begin{tabular}{|c|c|c|}
\hline \# lista & Candidato & Organización original11 \\
\hline 1 & Antonio Navarro Wolf & M-19 \\
\hline 2 & Carlos Ossa Escobar & Liberal \\
\hline 3 & Álvaro Leyva Duran & Conservador \\
\hline 4 & Rosemberg Pabón & M-19 \\
\hline 5 & José María Velasco & Conservador \\
\hline 6 & María Mercedes Carranza & Liberal, Nuevo Liberalismo \\
\hline 7 & María Teresa Garcés & Conservadora \\
\hline 8 & Héctor Pineda & M-19 \\
\hline 9 & Fabio de Jesús Villa & PCC, ML líder estudiantil \\
\hline 10 & Angelino Garzón & $\begin{array}{c}\text { Círculos Bernardo Jaramillo, líder sindical, } \\
\text { exmiembro de la UP }\end{array}$ \\
\hline 11 & Otty Patiño & м-19 \\
\hline 12 & Óscar Hoyos Naranjo & Anapo \\
\hline 13 & José Germán Toro & Líder sindical, Frente Popular \\
\hline 14 & Orlando Fals Borda & Académico, Colombia Unida \\
\hline 15 & Augusto Ramírez Cardona & Liberal, Frente Amplio del Magdalena Medio \\
\hline 16 & Abel Rodríguez & Líder sindical, Socialismo Democrático \\
\hline 17 & Germán Rojas Niño & M-19 \\
\hline 18 & Álvaro Echeverry & Académico, Círculos de Bernardo Jaramillo \\
\hline 19 & Francisco Maturana & dt Selección Colombia \\
\hline 20 & Marco Chalitas & м-19 \\
\hline 21 & Carlos Alonso Lucio & м-19 \\
\hline 22 & Luis Miguel Niño & Dirigente sindical de Boyacá \\
\hline 23 & Eduardo Chávez & м-19 \\
\hline 24 & Ricardo Villa & Liberal del Magdalena \\
\hline 25 & Ana Teresa Bernal & Líder femenina, miembro de Firmes \\
\hline 26 & Armando Novoa & Abogado y académico, profesor Universidad Libre \\
\hline 28 & Carlos Erazo & M-19 \\
\hline 29 & Camilo González & Abogado defensor de DD. Hн. del Tolima \\
\hline 30 & Yamel Riaño & M-19 \\
\hline 31 & Carlos Ramón González & M-19 \\
\hline
\end{tabular}

11 Por 'original' hacemos referencia aquí a la organización en la cual participaban los candidatos antes de vincularse a la ad-M-19. 


\begin{tabular}{|c|c|c|}
\hline 32 & Fabio Mariño & м-19 \\
\hline 33 & Marisol Isaza & Líder feminista \\
\hline
\end{tabular}

Fuente: elaboración propia.

El 9 de diciembre de 1990 la lista del M-19 obtuvo una contundente victoria que superaba los votos del mismo Navarro en las elecciones presidenciales de mayo. Cerca de un millón de sufragios respaldaron la lista del nuevo partido, superior al Partido Conservador y equivalente a las listas del Partido Liberal, dispersas en una conocida operación avispa. Era, en efecto, el momento de oro de la AD, que los llenó de suma confianza y cuando sus líderes interpretaron que la victoria sobre el modelo bipartidista estaba muy cercana. 19 nombres de la lista resultaron ganadores y participaron en una asamblea de 70 constituyentes. La AD obtuvo cerca de un tercio de las curules. Sin embargo, al mirar la lista en detalle se pueden apreciar las contradicciones en la orientación de Navarro. De los 19 constituyentes, solo seis eran antiguos combatientes del M-19: tres pertenecían a las filas del partido conservador y otros tres, a las toldas liberales. Del sector sindical hubo tres miembros; a estos se unirían un líder estudiantil y un curtido dirigente de la Anapo. Por el M-19 los elegidos fueron alguno de sus líderes históricos. El primero, cabeza de lista, fue Antonio Navarro, quien había renunciado al ministerio de Salud y dejó en su lugar a Camilo González Posso, miembro de la $\mathrm{AD}^{12}$. Luego, estaba otro histórico, Otty Patiño. Valluno y jefe de las redes urbanas de la guerrilla, Patiño fue uno de los hombres de mayor confianza de Carlos Pizarro.

Después vino el voto regional y sus cuotas. Los departamentos del Valle del Cauca y Atlántico fueron siempre fortines clave en términos electorales para la Alianza. Estos dos departamentos aportaron 200.000 votos para la Asamblea, un quinto del total. Teniendo en cuenta que Bogotá y Cundinamarca proporcionaron otros 200.000 votos, el impacto electoral del Valle y del Atlántico fue sumamente relevante para el partido. En ese orden de ideas, la lista tuvo dos representantes por el Valle y

12 En una entrevista hecha por Semana a Navarro el 16 de octubre de 1990, el líder de la AD tenía un marcado tinte caudillista, característico de sus años en la dirección de la organización:

La pregunta es si Navarro está dispuesto a dejar el ministerio de Salud para encabezar la lista del M-19, y si García Márquez está dispuesto a regresar a Colombia. Semana consultó al respecto al Ministro, quien contestó que las posibilidades de que se retire son del $50 \%$, por la sencilla razón de que el м-19 no tiene fuerza propia como movimiento, sino fuerza caudillista alrededor de la figura de Navarro. Si no encabeza él, lo harían personas como Rosemberg Pabón o militantes de ese nivel que podrían bajar la votación a la mitad. 
Atlántico. El primero fue Rosemberg Pabón, histórico del M-19 y figura muy reconocida en el Valle, quien posteriormente llegaría a ser alcalde de Yumbo. Por el Atlántico, Héctor Pineda partició en la lista, un arquitecto barranquillero no tan reconocido en la guerrilla como el anterior político. Su apreciación se dio gracias a la inmensa confianza de Carlos Pizarro en el marco de las negociaciones de paz de 1989. Pineda se convirtió en hombre de confianza y estafeta de Pizarro en los últimos años de la guerra. Su origen barranquillero y su amplio reconocimiento en el Atlántico le valieron ser incluido en la lista y, así, resultar elegido. El último de los elegidos, quien figuró en los últimos lugares de la lista, fue Germán Rojas Niño, conocido en las filas del M-19 como 'Raulito', quien al interior de la organización gozaba de mucha legitimidad entre sus compañeros; durante la guerra demostró todos sus dotes de militar y líder carismático. Tal vez su cualidad más destacada fue que, a pesar de ser un cuadro dentro de la organización, siempre dejo atrás el espíritu caudillista y demostró una gran modestia, por lo menos en términos políticos y públicos. Posterior a la renuncia de Francisco Maturana a su curul, tomó su lugar Marcos Chalitas, otro de los grandes cuadros de la guerrilla, con un importante ascendente dentro de las filas rurales y ficha clave en la comandancia de las tropas en el sur del país. Después de Boris ${ }^{13}$, Chalitas representó a los sectores campesinos dentro de las filas del M-19.

Tres reconocidos conservadores representaron a la AD en la Asamblea. El primero fue Álvaro Leyva Duran, abogado y economista que conocía como nadie los procesos de paz, pues había participado en casi todos. Había sido varias veces congresista en nombre del Partido Conservador. Navarro le reconocía así a Leyva su larga trayectoria en la busca de la paz y su gran cercanía tanto con el M-19 como con las FARC. El segundo fue José María Velasco, veterano conservador de Nariño, donde fue gobernador, por lo cual era muy cercano a Navarro. Velasco había sido también magistrado de la Corte Suprema. En los duros años de la represión de Turbay fue, junto con Carlos Cipagauta, un abogado defensor de los presos políticos de la Picota. Allí comenzarían sus nexos con la organización guerrillera, sin llegar nunca a aprobar su lucha armada. Por último, estaba María Teresa Garcés, otra de las cuotas de Navarro. Garcés

13 Boris era el nombre de guerra de Gustavo Arias Londoño. Este abogado antioqueño fue uno de los fundadores y cuadros militares del M-19. Estaba llamado a ser uno de los dirigentes de la organización, pero fue asesinado en julio de 1986, tan solo algunos meses después de la desaparición de Álvaro Fayad. 
era una reconocida líder conservadora del Valle, donde desarrolló gran parte de su carrera como abogada. Luchó en los años ochenta por temas de alto impacto social; Navarro la conocía desde los tiempos en que era un activista político en la Universidad del Valle. Había sido previamente magistrada del Tribunal Contencioso Administrativo del Valle; además, se desempeñó como viceministra de Comunicaciones en la administración de Belisario Betancur.

De la lista se destacan dos grandes académicos e intelectuales. Por un lado, estaba Álvaro Echeverri, polémico personaje, brillante abogado y académico, muy ligado a las filas de la rama judicial, ya que fue magistrado. Fue profesor en diversas universidades y, tal como Velasco, fue un abogado defensor de los presos de la Picota a principios de los años ochenta. Sin haber sido miembro efectivo de la UP, Echeverri acompañó a Bernardo Jaramillo en los últimos meses de su vida como un asesor para temas constitucionales. Por otro lado, estaría el profesor Orlando Fals Borda, fundador de la Facultad de Sociología de la Universidad Nacional, junto con Camilo Torres. Fuerte activista político, terminaría encerrado y torturado, junto con su esposa María Cristina al inicio de los ochenta como consecuencia de la cacería de brujas del gobierno de Turbay, gracias al Estatuto de Seguridad. Fals Borda no militaba en el M-19, pero su activismo político era muy reconocido. Era el dirigente más prominente de lo que en los ochenta se conocía como "Colombia Unida".

Los sectores sindicales aportaron tres nombres a la lista. Dada la cercanía entre el M-19 y los trabajadores, estos últimos estarían en estrecho contacto con Navarro después de la desmovilización y tendrían un papel significativo en la AD en los siguientes años. El primero fue José Germán Toro, quien, para el momento, era el presidente de la Federación Colombiana de Educadores (Fecode) y uno de los más fuertes activistas del movimiento que se disolvió en la AD, conocido como Frente Popular.

El segundo nombre de los sindicalistas fue Abel Rodríguez, también del sector de los educadores, y quien tendría un papel directivo en la AD en los siguientes años. Llegó a ser concejal de Bogotá por el movimiento Socialismo Democrático y fue uno de los enlaces más fuertes de la AD con la Internacional Socialista.

Por los sectores que habían abandonado las filas de la UP, denominados ahora "Círculos Bernardo Jaramillo" (СBJ), se encontraba Angelino Garzón. Este líder sindical de la Federación Nacional de los Trabajadores al Servicio del Estado, fue de las figuras más emblemáticas de los reductos de la up que se distanciaron del PCC. Junto con Diego 
Montaña Cuellar, buscaron consolidar un nuevo movimiento de izquierda democrática por fuera de la tendencia comunista.

Las toldas liberales tuvieron también tres representantes. Primero, Carlos Ossa Escobar fue un curtido liberal que había participado en la administración de Virgilio Barco. Como comisionado de Paz, antes de ceder su puesto a Rafael Pardo, inició los acercamientos con Carlos Pizarro y la Coordinadora Guerrillera Simón Bolívar. Por muchos años estuvo atado al mundo agrario. Esto lo llevó a ser viceministro de agricultura y, posteriormente, presidente de la Sociedad de Agricultores de Colombia Ossa había sido candidato a la Alcaldía de Bogotá, compitiendo contra Pizarro en 1990. A pesar de esto, siempre mantuvo estrechos contactos con Navarro.

Por otro lado, María Mercedes Carranza ${ }^{14}$ buscaba abrir el espacio no solo a lo cultural, sino a las reivindicaciones de género dentro de la ANC. Carranza se había unido al proyecto de Luis Carlos Galán y militó en el Nuevo Liberalismo desde su fundación. Se desempeñó como jefe de redacción de la revista Nueva Frontera. Antes de fungir como constituyente, fue directora de la Casa de Poesía Silva.

Por último, Augusto Ramírez Cardona fue un experimentado y polémico dirigente político liberal en Caldas. Además de médico, fue ganadero. Su reconocimiento y profesión lo llevaron a establecer contactos con el Frente Amplio del Magdalena Medio. No se puede descartar que haya tenido nexos con el paramilitarismo.

Cabe mencionar dos casos excepcionales. Por un lado, Óscar Hoyos Naranjo, veterano político de Antioquia, en los años setenta, apoyó a Rojas Pinilla en la Anapo; desde entonces había sido un fiel militante de este partido, sin importar su casi total desaparición. Como representante de este partido fue congresista, concejal de Medellín y diputado del departamento. Fue hermano del sacerdote Bernardo Hoyos, quien luego sería alcalde de Barranquilla representando a la AD. Por otro lado, el constituyente más joven de la Asamblea fue Fabio Villa. Al igual que Hoyos, venía de Antioquia; no obstante, para finales de los ochenta se trasladó a Bogotá, ya que estudió Sociología en la Universidad Nacional. Se dio a conocer como líder estudiantil a principios de los noventa con el despertar de los

\footnotetext{
14 Resulta por demás significativo que la participación de las mujeres fue muy baja en la Asamblea Nacional Constituyente. De ese bajo porcentaje el M-19 contribuyo con dos nombres, pero ninguno de ellos correspondió a alguna de las militantes de la guerrilla del M-19. Sin duda la que más renombre poseía era Vera Grabe, pero ella ya se encontraba cumpliendo sus funciones como representante a la Cámara. Otros nombres como los de Gloria Quiceno o María Eugenia Velásquez hubieran podido estar allí, pero no fue parte de la decisión de Navarro.
} 
estudiantes, pues promovió la séptima papeleta. Nunca logró establecer acuerdos fluidos con Fernando Carrillo, quien lideraba el movimiento Todavía Podemos Salvar a Colombia, que aglutinaba a las universidades privadas. Por este motivo, Villa fundo el movimiento de estudiantes de universidades públicas, conocido como "Movimiento Universitario por la Constituyente", que actuó de forma paralela al de Carrillo.

Desde hombres políticos con posibilidades de llegar a la presidencia de Colombia tales como Antonio Navarro hasta entrenadores de futbol como Maturana, pasando por liberales, conservadores, anapistas, sindicalistas y poetas, consolidaron la lista de la AD, que terminó imponiéndose en las urnas. Este grupo de constituyentes construiría la nueva carta política de los colombianos a lo largo del primer semestre de 1991. Una lista diversa hasta en lo regional, especialmente en aquellos departamentos en donde la AD era muy fuerte. Fue una de las bancadas más grandes y más diversas. En la línea del "gran sancocho nacional" del que hablaba Bateman, se conformó una lista que buscaba ser amplia y diversa. Sin embargo, fue, tal vez, esa diversidad lo que la desdibujó no solo ante sus militantes, sino sobre todo ante sus votantes, la marca y la esencia de lo que otrora representara el M-19 y los diversos sectores de la izquierda democrática.

El jefe de la AD justificó siempre su lista como una muestra de pluralidad, tratando de probar que su nuevo partido no era sectario, por el contrario, estaba abierto a muchas posiciones. Empero, esta pluralidad era excesiva según algunos de los militantes de la Alianza. Creían que tanta apertura desconfiguraba una posición política clara frente al electorado, que el respaldo de los votantes respondía al legado de Pizarro antes de morir y al de Navarro, más que a la coherencia de una lista con una doctrina política definida. Además, creían que la lista seleccionada correspondía a un oportunismo político de algunos personajes que verían en la AD-M-19 un nombre con buena aceptación en la sociedad que les podría llevar a ganar la curul.

\section{EL TREN DE LA CONSTITUYENTE SE PONE EN MARCHA. FEBRERO-JULIO DE 1991}

La ANC comenzó a sesionar formalmente el 5 de febrero. Aquel día se llevó a cabo una reunión en el Capitolio Nacional, pero la incomodidad estaba a la orden del día. Al lado de los constituyentes estaban los parlamentarios, 
quienes veían como principal amenaza de sus posiciones a la ANC. Por este motivo, las sesiones de la Asamblea se trasladadaron al Centro de Convenciones Gonzalo Jiménez de Quesada el 6 de febrero (Garzón, 2018). La presidencia de la Asamblea estuvo las primeras horas en manos de Aida Abello y Carlos Daniel Abella. Esta designación procedió por temas de orden alfabético ${ }^{15}$. Sin embargo, ese no era el tema de fondo. La ANC resultaba ser el fiel reflejo del país político y las tensiones no se hicieron esperar. Las fuerzas que habían sido favorecidas se imponían para alzarse con la presidencia de la Asamblea. Así las cosas, los primeros días de la Asamblea se dedicaron a zanjar este tema y crear un reglamento de la Asamblea misma. Para el espinoso tema de la presidencia muchas opciones fueron barajadas. Allí, las astucias políticas de Antonio Navarro, Álvaro Gómez, Horacio Serpa y Jaime Castro afloraron sin dar espera. Este relato resalta una de las múltiples tensiones que se dieron al respecto. La presidencia colegiada se definió entre las tres fuerzas hegemónicas dentro de la Asamblea, lo cual marcaría los destinos de los meses que vendrían. En cuanto a las reglas de funcionamiento, Zuluaga resume claramente el modo de funcionar de la Asamblea para aprobar la nueva carta magna:

[...] las propuestas se estudiaban en subcomisiones, de donde pasaban a una de las 5 comisiones. Posteriormente, la plenaria las aprobaba en primer debate y de allí se enviaban a la Comisión Codificadora, de donde volverían al pleno para un segundo debate, en el que cada artículo propuesto debía alcanzar una mayoría aprobatoria cualificada de dos terceras partes de los delegatarios (Zuluaga, 2008, p. 105).

La AD-M-19 poseía una de las bancadas más importantes de la Asamblea, por lo que pudo participar en las cinco comisiones que se conformaron, según los intereses los miembros de la bancada. No obstante, resulta diciente que un grupo importante de constituyentes quisieron vincularse a la primera comisión, que es la que definía la parte dogmática de la carta magna. No sorprende que Orlando Fals se haya vinculado a la comisión de ordenamiento territorial dada su trayectoria académica e intelectual

15 Según las entrevistas realizadas, ocurrió una curiosa anécdota en esos momentos, que, a pesar de no tener una trascendencia histórica, nos permitimos brevemente señalar aquí. La forma correcta de escribir el nombre de Aida Abello es "Aida Avello". Algunos constituyentes se quejaron de que la representante de la up hiciera un ajuste ortográfico, para ser la primera en la lista. De no haberlo hecho, no hubiera podido ser presidente de la anc, pues hubiera tenido que cederle el turno a Jaime Arias López. 
que se había orientado hacia dicho tema. Tampoco es de admirar que Navarro participara en la definición de la rama ejecutiva dadas sus claras aspiraciones no solo a ser presidente, sino a tratar de abrir un espacio para su partido en el sistema político ${ }^{16}$. A pesar de que la comisión definía el futuro y funcionalidad de las Fuerzas Armadas, no promovió cambios sustanciales. Garcés y Velasco fueron dos de los constituyentes más dinámicos de la bancada haciendo propuestas y debates. Ayudaron a diseñar propuestas innovadoras, como la Corte Constitucional, la Fiscalía y la Defensoría del Pueblo. Angelino Garzón también se destacó, ya que movilizó y apoyó diversas propuestas en todo lo referente a temas laborales medioambientales. Sin embargo, mientras que Garzón se convirtió en el defensor de los sectores trabajadores y populares, Ossa, en la misma comisión, se convirtió en el defensor del modelo neoliberal que habría de regir a futuro el país.

Tabla 2. Miembros de la AD-M-19 en las comisiones de la ANC

\begin{tabular}{|c|c|}
\hline COMISIÓN & MIEMBROS AD-M-19 \\
\hline $\begin{array}{l}\text { I. Principios, derechos, deberes, garantías y } \\
\text { libertades fundamentales }\end{array}$ & $\begin{array}{l}\text { María Mercedes Carranza } \\
\text { Marco Chalitas } \\
\text { Álvaro Leyva Duran } \\
\text { Otty Patiño } \\
\text { José Germán Toro }\end{array}$ \\
\hline II. Ordenamiento Territorial del Estado & $\begin{array}{l}\text { Orlando Fals Borda } \\
\text { Héctor Pineda Salazar } \\
\text { Augusto Ramírez Cardona }\end{array}$ \\
\hline $\begin{array}{l}\text { III. Gobierno, Congreso, Fuerza Pública, estado de } \\
\text { Sitio y Relaciones Internacionales }\end{array}$ & $\begin{array}{l}\text { Álvaro Echeverry } \\
\text { Antonio Navarro Wolf } \\
\text { Rosemberg Pabón } \\
\text { Fabio Villa } \\
\text { Abel Rodríguez }\end{array}$ \\
\hline IV. Administración de Justicia y Ministerio Público & $\begin{array}{l}\text { María Teresa Garcés } \\
\text { José María Velasco }\end{array}$ \\
\hline
\end{tabular}

16 Ahora bien, sorprende más que otros "presidenciables" no hicieran parte de esta comisión. Álvaro Gómez prefirió vincularse a la cuarta; Jaime Castro, a la segunda; Horacio Serpa, a la primera, y Rodrigo Lloreda, a la quinta. 


\begin{tabular}{|l|l|}
\hline \multirow{2}{*}{ V. Asuntos económicos, sociales y ecológicos } & Angelino Garzón \\
& Óscar Hoyos Naranjo \\
& Carlos Ossa Escobar \\
& Germán Rojas Niño \\
\hline
\end{tabular}

Fuente: Gaceta Constitucional (1991).

Todos los constituyentes, partidos o agrupaciones políticas presentes en la anc tenían el derecho a presentar reformas a la constitución. Estas propuestas podían ser individuales, colectivas o, en determinados casos, darse a través de un partido político. Igualmente se podían presentar reformas que trataran todos los temas de la constitución o bien propuestas parciales, que podrían incluir un solo artículo o hablaban únicamente del preámbulo. El plazo para presentar las propuestas fue el 26 de marzo y estas deberían ser tramitadas ante el secretario de la ANC, Jacobo Pérez Escobar. Se propusieron 152 proyectos constitucionales, de los cuales 26 fueron presentados por externos a la ANC, tales como el Gobierno nacional, las altas cortes, el ministerio público, universidades, entre otros ${ }^{17}$.

Tabla 3. Trámite de proyectos constitucionales Asamblea Nacional Constituyente

\begin{tabular}{|c|c|c|c|}
\hline Partido / Agrupación & $\begin{array}{c}\text { Proyectos } \\
\text { integrales }\end{array}$ & $\begin{array}{c}\text { Proyectos } \\
\text { parciales }\end{array}$ & Total \\
\hline Liberales & 8 & 43 & 51 \\
\hline msn & 3 & 31 & 34 \\
\hline ad-m-19 & 2 & 14 & 16 \\
\hline Conservadores & 1 & 10 & 11 \\
\hline Otros & 2 & 12 & 14 \\
\hline TOTAL & 16 & 110 & 126 \\
\hline
\end{tabular}

Fuente: Gaceta Constitucional (1991).

El 19 de febrero de 1991, dos semanas después del inicio de las sesiones de la Asamblea y de haber superado los temas del reglamento y la presidencia de la Asamblea, la AD presentó su propuesta de reforma constitucional. Las líneas centrales de esta son la consolidación de una verdadera democracia, plural y abierta, basada en el respeto de las más diferentes creencias a

17 Continuando con las anécdotas, se pueden hacer muchos análisis de las propuestas registradas en la Gaceta Constitucional. Solo queremos destacar la propuesta integral presentada por el constituyente Alberto Zalamea, quien propuso a la anc exactamente la misma constitución redactada por Núñez y Caro en 1886. 
través de un Estado de derecho efectivo y desde luego bajo un contexto de paz tanto política como social. Insiste esta de forma significativa en la importancia de las relaciones internacionales y de cómo el país debe abrirse a los diversos escenarios (Gaceta Constitucional, 1991).

Los cambios propuestos por la AD al inicio de la asamblea se resumieron en un primer borrador de constitución de alrededor de 190 artículos. Los elementos centrales que englobaban esta propuesta eran los siguientes:

- Una democracia participativa y representativa,

- Una autonomía territorial,

- Una equidad social,

- Una moralización de la gestión pública, y

- Una modernización de las instituciones.

La estrategia de Navarro en la constituyente, junto con los miembros de la $\mathrm{AD}$, otros partidos como la UP, indígenas y otros desmovilizados, se enfocó en:

- Reformar al Congreso y revocarlo.

- Crear la vicepresidencia y la segunda vuelta ${ }^{18}$.

- $\quad$ Elección de gobernadores ${ }^{19}$.

- Unicameralismo con cien diputados.

- Un esquema menos presidencialista.

- Nuevo régimen de partidos políticos.

Revisando con atención y de forma sucinta la propuesta integral de la AD, hay una lucha transversal por el fortalecimiento y ampliación de la democracia, que se expresa en una mayor participación civil y política de la ciudadanía, así como en derechos más amplios con mejores garantías. Dentro de la propuesta resaltamos tres aspectos fundamentales: una amplia y ambiciosa reforma económica, la reestructuración del Estado y la administración pública, y una reforma electoral y legislativa. Empero, además de la reforma del Estado y una nueva concepción de la política, Navarro se propuso, a través de la ANC, abrir un nuevo espacio político para su partido. Se trató de consolidar a la Alianza mejorar las oportunidades de Navarro de llegar a la presidencia de la república (Fajardo, 2018).

18 Es posible que Navarro y la AD buscaran con la segunda vuelta y la fórmula vicepresidencial cambiar el esquema político. Se trataba especialmente de romper el bipartidismo con la entrada de un tercer partido que, en la línea de Sartori, pudiera ser decisivo en esa ruptura.

19 Esto se proponía ampliar el espectro territorial en términos electorales y lograr consolidar el partido desde un punto de vista regional. 
En los aspectos económicos, estaba tal vez lo más audaz y ambicioso de la propuesta de la AD. No parecía unánime la posición dentro de la bancada sobre este punto; hubo una particular incomodidad por parte de Carlos Ossa, quien se veía en una esquina más bien liberal. Solo Ossa defendió este tipo de planteamientos, que no dejaron de ser polémicos. Justamente lo contrario a esta visión se ve en la propuesta del 19 de febrero. El alma de la propuesta económica es la lucha contra el neoliberalismo, con una insistente defensa de las empresas públicas, además de un Estado más dinámico y activo en la propiedad de las empresas. También hubo un considerable modelo de intervención estatal de la economía, a la vez de una lucha contra los monopolios. Adicionalmente, constituyentes como Angelino Garzón insistieron en la cogestión de patrón y empleado, así como la participación de los trabajadores en las utilidades de las empresas. Claramente esta propuesta tocaba fibras sensibles de las élites económicas del país y que prendía las alarmas tanto de empleadores como de sectores tradicionales de la política. A pesar de la fuerza de la AD en la Asamblea, estas propuestas tuvieron poca acogida. Se terminó debatiendo y aprobando la propuesta del gobierno de Gaviria, mucho más austera en términos de derechos sociales. Asimismo, la AD entró en sintonía con otros sectores de la Asamblea ante la propuesta de una mayor independencia y autonomía para el Banco de la República. Se plantearon nuevos y más eficientes métodos de planeación publica y, desde luego, un manejo más regulado de la deuda externa (Gaceta Constitucional, 1991).

Si bien la reforma de Estado propuesta por la AD no era un cambio sustancial respecto a la Constitución de 1886, hubo novedades, de las cuales esta bancada no sería la única defensora. La AD propuso crear la Fiscalía General de la Nación, basada en el modelo norteamericano. También insitió en la adecuación del Ministerio Público, lo que le dio mayores funciones a la Procuraduría. De la misma forma, fortaleció la protección de los derechos humanos a través de la Defensoría del Pueblo. Igualmente propuso cerrar la Contraloría, organización de gran tradición en el país, pero que, para finales de los ochenta, se había convertido en un enorme foco de corrupción. Para reemplazar a la Contraloría se propuso crear una corte de cuentas, dirigida por un cuerpo colegiado de magistrados elegidos por el Consejo de Estado. Por último, esta reforma trató de crear un tribunal supremo electoral, conformado por nueve magistrados designados por la Corte Suprema de Justicia. Este ofrecería mayores garantías y transparencia en los procesos electorales, a la par de sustentar un nuevo régimen de partidos políticos. Llama la atención 
que dentro de esta propuesta general no se incluya la creación de la Corte Constitucional, como lo hicieron otras bancadas. No obstante, la insistencia de María Teresa Garcés permitió que se terminará avalando esta propuesta (Gaceta Constitucional, 1991).

La propuesta de la AD innovó en asuntos en torno a las elecciones, el legislativo y el ejecutivo. Desde antes de la de la AnC, Navarro y la bancada de la AD habían dicho que era necesario revocar el Congreso. Los constituyentes consideraban que no era posible entregarle la nueva carta a los viejos legisladores para que la destruyeran. Una vez revocado el Congreso se proponía crear un legislativo denominado "asamblea nacional de carácter unicameral", con cien diputados, renovables en parte cada dos años y de circunscripción nacional. Desde luego, y uno de los grandes caballos de batalla de la época, se proponía eliminar los auxilios parlamentarios. En términos electorales, se planteaba el tarjetón como forma definitiva de elección, dejando atrás las papeletas. Más allá de esto, una propuesta muy conveniente para el sistema político colombiano fue elegir el Congreso y la Presidencia el mismo día, para evitar los movimientos clientelistas y la compra de votos entre las dos elecciones, como sucede actualmente. En lo que refiere al ejecutivo, se planteó crear la vicepresidencia y la elección presidencial a dos vueltas (Gaceta Constitucional 1991).

Otras disposiciones de orden general están consignadas en la propuesta de la Alianza; se convirtieron en algunos momentos en algo innovador y de alguna manera representaron lo que la guerrilla del M-19 planteó en sus años de lucha armada. La propuesta contenía crear lo que 20 años después se conoció como la Comisión Nacional del Servicio Civil. Implementar este organismo buscaba mejorar y equilibrar el acceso a la carrera de la función pública. Esto evitaría que estos puestos fuesen utilizados con un fin clientelista. Con referencia al estado de sitio, un hecho se convirtió en un tema de honor. Varios de los constituyentes habían sufrido los embates de esta figura en años precedentes. Por esto, la regulación de esta práctica, así como su control, se convertían en uno de los aspectos no negociables para la Alianza. También se reglamentó el habeas corpus y se ofrecieron garantías para que no se torturara en el país. De igual forma, hubo medidas especiales en temas de medio ambiente, de género, la educación, el ordenamiento territorial, la salud y la protección de las riquezas nacionales. Una última propuesta, polémica y que se hundió rápidamente en la Asamblea, era que la mayoría de edad pasara de 18 a 16 años. 
Más allá de proponer la reforma general, lo cual los 19 constituyentes de la bancada firmaron, que tendría una versión corregida semanas después, los miembros de la AD registraron otras reformas individuales o grupales. En el siguiente cuadro se puede apreciar los temas en los que se enfocaron cada uno de los constituyentes.

Tabla 4. Trámite de proyectos AD-M-19, por constituyente o grupo de constituyentes

\begin{tabular}{|c|c|}
\hline Autor & Título de la Reforma \\
\hline Francisco Maturana & $\begin{array}{l}\text { - Derechos, garantías y deberes del ciudadano colombiano. } \\
\text { Derecho al deporte. }\end{array}$ \\
\hline Abel Rodríguez y José Toro & - Reforma democrática de la educación. \\
\hline María Teresa Garcés & $\begin{array}{l}\text { - Reforma de administración de justicia, estado de sitio y } \\
\text { creación de la rama de control. } \\
\text { - Administración de justicia. Consejo Superior de la Judicatura. } \\
\text { - Control constitucional, Corte Constitucional y Corte Suprema } \\
\text { de Justicia. } \\
\text { - Ampliación de la democracia. } \\
\text { - El papel de la oposición y los partidos de oposición, así como } \\
\text { - Control a los auxilios parlamentarios. } \\
\text { - Defensor del pueblo. } \\
\text { - Fiscalía General de la Nación. }\end{array}$ \\
\hline Fabio Villa & 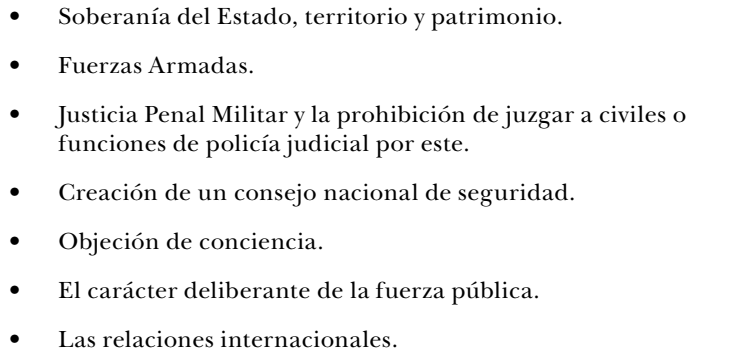 \\
\hline Antonio Navarro y Fabio Villa & - $\quad$ El Estado de sitio y de excepción. \\
\hline $\begin{array}{l}\text { María Mercedes Carranza y } \\
\text { Álvaro Leyva }\end{array}$ & - Medios de información y de comunicación. \\
\hline Antonio Navarro & $\begin{array}{ll}\text { - } & \text { Reforma constitucional. } \\
\text { - } & \text { Sobre la función del vicepresidente. } \\
\text { - } & \text { De la segunda vuelta presidencial. } \\
\text { - } & \text { Estructura del Estado. } \\
\text { Rama ejecutiva del poder público. }\end{array}$ \\
\hline $\begin{array}{l}\text { Germán Rojas, Angelino } \\
\text { Garzón y Abel Rodríguez }\end{array}$ & - Plan de alivio social. \\
\hline Abel Rodríguez & - $\quad$ Servidores públicos. \\
\hline
\end{tabular}




\begin{tabular}{|c|c|}
\hline Germán Rojas & $\begin{array}{l}\text { - } \\
\text { - } \quad \text { Plantrol fiscal. } \\
\text { - Hación. } \\
\text { Haciendo pública. }\end{array}$ \\
\hline Carlos Ossa & $\begin{array}{l}\text { - Regulación económica y contratación por parte del Estado. } \\
\text { - Democratización de la economía. }\end{array}$ \\
\hline Carlos Ossa y Óscar Hoyos & $\begin{array}{l}\text { - } \quad \text { Régimen económico y finalidad social del Estado. } \\
\text { - } \quad \text { Banca central. } \\
\text { internacionalización de las relaciones económicas e } \\
\text { - } \quad \text { Deuda externa y régimen de aduanas. } \\
\text { - } \quad \text { Estado de emergencia económica. } \\
\text { - Atribuciones económicas del congreso. }\end{array}$ \\
\hline Augusto Ramírez Cardona & $\begin{array}{l}\text { - } \quad \text { Derechos de familia. } \\
\text { - } \quad \text { Servicios públicos. }\end{array}$ \\
\hline Orlando Fals y Héctor Pineda & $\begin{array}{l}\text { - De las entidades territoriales. } \\
\text { - Ordenamiento territorial. }\end{array}$ \\
\hline Orlando Fals Borda & - Provincias y asociaciones de municipios. \\
\hline $\begin{array}{l}\text { Antonio Navarro y Abel } \\
\text { Rodríguez }\end{array}$ & - Sistema de segunda vuelta electoral. \\
\hline Otty Patiño & $\begin{array}{l}\text { - Partidos, sistema electoral y estatuto de la oposición. } \\
\text { - Los fines del Estado }\end{array}$ \\
\hline Héctor Pineda & $\begin{array}{l}\text { - Los municipios y la descentralización } \\
\text { - Áreas metropolitanas, asociaciones de municipios y distritos } \\
\text { metropolitanos. }\end{array}$ \\
\hline Angelino Garzón & 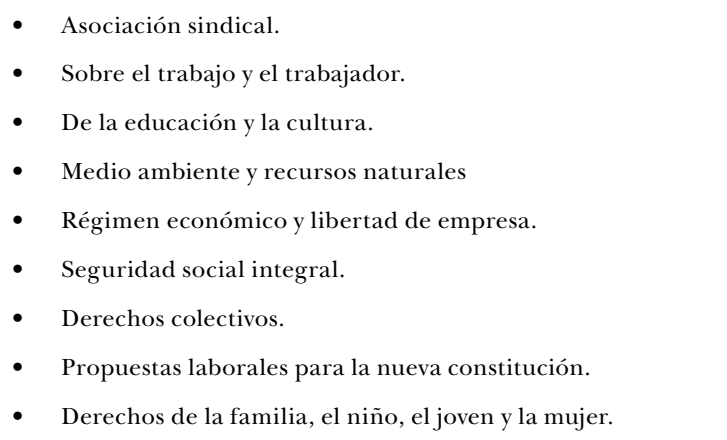 \\
\hline $\begin{array}{l}\text { Álvaro Echeverry y Rosemberg } \\
\text { Pabón }\end{array}$ & $\begin{array}{l}\text { - } \quad \text { Sobre la función legislativa. } \\
\text { - } \quad \text { Estatuto del congresista. } \\
\text { - Congreso unicameral. }\end{array}$ \\
\hline José María Velasco & - Creación de la Corte Constitucional. \\
\hline
\end{tabular}

Fuente: Gaceta Constitucional (1991). 
En realidad, este cuadro refleja tanto la actividad como las áreas de interés de los diversos constituyentes. Sus posiciones, preferencias y tendencias se ven en las comisiones en donde los miembros de la bancada de la AD participaron. Desde luego, los intereses personales y colectivos, las visiones de futuro y las áreas de experiencia intervinieron para la acción de esta bancada. Como en toda bancada, hubo miembros bastante destacables; otros sobresalieron en el apoyo a proyectos puntuales, y otros tuvieron un papel marginal.

Vale la pena resaltar, en lo que refiere a la bancada de la $\mathrm{AD}$, el papel de María Teresa Garcés, quien a nuestro juicio fue la constituyente más destacada dentro de la Asamblea, no solo por la cantidad de propuestas registradas, sino por la calidad de sus debates y su argumentación, e incluso por su posición en ciertos aspectos clave en contra del grueso de la bancada ${ }^{20}$. Garcés fue fundamental en muchos de los aspectos aún vigentes y claves en nuestro desarrollo institucional. También mostraron una calidad, disciplina y rigor en su trabajo Angelino Garzón ${ }^{21}$, Orlando Fals y Fabio Villa, cuyas propuestas y promoción de los debates abundaron durante los cinco meses de la ANC. Antonio Navarro tenía claro el rumbo de las iniciativas sobre el Estado, la rama ejecutiva y, en especial, el poder presidencial. Junto con él actuaron Rosemberg Pabón, Otty Patiño y Marco Chalitas, quienes más que iniciativas propias se dedicaron a apoyar la labor de Navarro. El grueso de la bancada de la AD mantuvo una posición consecuente con las líneas centrales del partido. Sin confrontarse directamente con el establecimiento a través de medidas radicales, se buscaron implementar disposiciones progresistas, así como reformas clave al Estado ${ }^{22}$. Solo dos de los constituyentes fueron intrascendentes, Óscar Hoyos y Augusto Ramírez. Estos dos constituyentes participaron muy poco

\footnotetext{
20 Garcés y María Mercedes Carranza no aprobaron la no extradición. Garcés se oponía igualmente a la aprobación del régimen económico propuesto por su compañero de bancada Ossa Escobar, ya que lo consideraba una puerta abierta al neoliberalismo. Ella y Carlos Lleras de Fuente tuvieron la dura tarea de unificar los textos de la Asamblea que se iban aprobando en primer debate. Estos ejemplos nos hablan del fuerte dinamismo de esta constituyente.

21 Vale la pena resaltar que el trabajo de Garzón fue muy dinámico y propositivo; la mayoría de sus propuestas las hizo en compañía de Tulio Cuevas.

22 Sin duda el aporte de la AD-M-19 resulta significativo. Organismos como la Fiscalía General de la Nación o la Corte Constitucional fueron impulsadas, no de forma exclusiva, por esta bancada. Asimismo, la elección popular de gobernadores y la descentralización territorial fueron importantes luchas dadas al interior de la Asamblea. Los derechos de los trabajadores fueron defendidos igualmente allí, lo cual tuvo resultados significativos. La creación de la figura del vicepresidente, discutible; la doble vuelta presidencial; el tarjetón electoral, y el planteamiento de un estatuto de la oposición son aportes destacables de la AD-M-19. Normativas para controlar el fenómeno de la corrupción, la defensa de los derechos humanos y el final del estado de sitio fueron igualmente valiosas contribuciones de la AD-M-19.
} 
en los debates; sus propuestas fueron escasas. Augusto Ramírez mostró inexperiencia y desidia; su aporte fue mínimo y pasó casi inadvertido por la Asamblea, de no ser por el bochornoso escándalo del cual fue protagonista $^{23}$. Por último, tenemos que señalar el caso de Carlos Ossa, cuyo papel fue inconsecuente con las líneas generales planteadas por la AD. Su postura, especialmente económica, buscaba fortalecer un Estado neoliberal, altamente criticado por muchos de los miembros de la propia Alianza. En líneas generales, los miembros de la bancada de la AD aportaron al desarrollo de esta a su manera. Algunos con mayor independencia, otros más bien sumamente ceñidos a las directrices de Navarro. La AD era la única bancada, de acuerdo con los testimonios, que se reunía de forma casi religiosa todas las noches después de las deliberaciones y discusiones de la Asamblea. Esas reuniones eran dirigidas por Navarro, buscaban hacer el balance de la jornada y mostrar las directrices de los debates que seguían.

En suma, la bancada de la AD buscaba implementar un sistema político y electoral más abierto que pudiera darle cabida a su propuesta alternativa. Buscaba atacar a la vieja clase política de los partidos tradicionales. Navarro y su bancada trataron de evitar la confrontación en temas realmente sensibles, por ejemplo, la propiedad privada, la extradición o las fuerzas armadas. El partido no quería mostrarse como el gran reformador que iba a refundar la república, a pesar de su peso dentro de la ANC. Por el contrario, trataba de ser el partido conciliador con aquellos sectores que fueran afines a sus objetivos políticos. Irse de frente contra la élite política tradicional, lo sabían bien, era una pelea perdida en un modelo como el colombiano. En realidad, en estas propuestas la AD hacía honor a las doctrinas políticas que desarrollaron durante la guerra. Su esquema político durante los años en armas, especialmente luego del proceso de paz con Betancur, resulta muy similar a lo que en líneas generales proponía la AD en la Constituyente ${ }^{24}$.

\footnotetext{
23 Según las entrevistas, los constituyentes tuvieron un desempeño adecuado. La única queja sensible fue de Otty Patiño en contra deAugusto Ramírez, quien terminó por enlodar el desarrollo de la ANC al final de sus sesiones. Ramírez, junto con la embajada de los Estados Unidos y algunos grupos paramilitares del Magdalena Medio, hizo un videomontaje en el que aparecían varios constituyentes recibiendo dos millones de pesos para votar a favor de la no extradición. Esta situación se dio, según Patiño, por el desencanto tanto de los norteamericanos como de los paramilitares enemigos de Pablo Escobar por la prohibición de la extradición, que terminaría consignada en la Constitución. Con este ese propósito advertía Zuluaga en una entrevista a Patiño: "[Ramírez] fue un tipo que nunca habló y que lo más notable que hizo fue esa payasada, que a la larga tampoco le sirvió a los gringos” (Zuluaga, 2008, p. 173).

24 Desde la toma de la Embajada de República Dominicana en 1980, este partido presentó un
} 
Esta estrategia de la AD recibió fuertes críticas por parte de los más diversos sectores. Por ejemplo, la Alianza no lograba poner en sintonía al conjunto de la izquierda colombiana. Aun en la década precedente, los sectores de la izquierda criticaron con ahínco a la guerrilla del M-19. En general, calificaban la postura de la bancada de la Alianza como tímida y poco comprometida con los problemas estructurales del país, así como sus instituciones. Además, señalaban que la bancada y, en especial, Navarro habían caído en el juego de los liberales y el presidente Gaviria. Otros sectores políticos también atacaron a la AD, en particular a su líder, Antonio Navarro. El principal argumento utilizado por la derecha era que durante la constituyente este había hecho gala de lo mejor de su populismo planteando reformas que tenían poco sustento. Si bien lo presentaron como una total amenaza antes del desarrollo de la Asamblea, para cuando estaba firmada la Constitución se le veía como un fenómeno político de mucho ruido y poca acción. Desde la izquierda, la derecha, los académicos, los intelectuales, hasta la prensa juzgaron tanto a Navarro como al fenómeno de la AD. La ambivalencia fue duramente cuestionada: se esperaba un discurso más radical, pero, como hemos señalado, la apuesta de la AD fue no confrontar a los sectores tradicionales, para obtener mayores réditos en un futuro y un mejor espacio dentro del sistema político colombiano.

Queremos cerrar este acápite mencionando un tema trascendental durante los meses que sesionó la Asamblea y después de estos, la revocatoria del Congreso. Resultó casi una cuestión de honor para la bancada de la AD y el MSN revocar el Congreso, pues consideraban que entregarle la nueva constitución al viejo Congreso, en julio de 1991, era la fórmula perfecta para que estos desarticularan el trabajo de la nueva carta magna. La revocatoria terminó por ser el plato principal de este variado menú que fue la ANC; se convirtió, a su vez, en el elemento de pugna política más significativa de ese semestre. Muchos constituyentes se quejaron de que el tema de la revocatoria le restó tiempo y energía a la Asamblea para otros temas igualmente trascendentales. La vieja clase 
política se enfrentaba a las nuevas propuestas y eso no dejo de generar múltiples rencillas.

Uno de los principales propulsores de la revocatoria del Congreso fue la AD; a este tren se subió posteriormente el MSN. Tal vez fue la única verdadera alianza entre estas dos organizaciones. En una reunión realizada en el Palacio de Nariño el 7 de junio de 1991 y liderada por Cesar Gaviria y Alfonso López se discutió la revocatoria del Congreso elegido en marzo de 1990. Esta unión resultaría vilipendiada como consecuencia de la aprobación, la noche del 7 de junio de 1991, que hizo Navarro a la propuesta del partido liberal de inhabilitar a los constituyentes para participar en el nuevo Congreso. Para los constituyentes, un factor clave para la aplicación de la nueva constitución era la renovación del Congreso, que debería aplicar la nueva carta magna. A juzgar por los testigos de excepción a esa reunión, el partido liberal en cabeza de López aprobaría la revocatoria del Congreso siempre y cuando se inhabilitara a los constituyentes que estaban redactando la nueva carta a participar de este. En realidad, se trataba de un golpe de astucia propiciado por un veterano de la política nacional. El sector que lideraba Álvaro Gómez estaba en total desacuerdo con esta propuesta; se opuso hasta el final a la reunión. El sector de la AD-M-19 debía inclinar la balanza, sin duda. Antonio Navarro decidió entonces apoyar las propuestas de López, a pesar de los múltiples argumentos de Gómez en contra. En palabras de Otty Patiño, constituyente y asistente a la reunión: "Antonio salió muy contento de aquella reunión. Creía haber salido ganador de la misma [sic.], pero lo cierto es que estaba en cierta medida castrando a los mejores cuadros del partido de hacer parte del nuevo congreso" (Patiño, 2018). En cierta forma, Navarro le cortó las alas y el impulso a la AD buscando hacer acuerdos con el gobierno de Gaviria y el partido liberal. Empero, la falta de experiencia llevó a que estos factores pasaran factura al movimiento en las elecciones que vendrían (Gaceta Constitucional, 1991) ${ }^{25}$.

Resultó curioso que en el curso de algo más de cuatro meses las tendencias y alianzas variaron considerablemente. Álvaro Gómez y su bancada tuvieron serias diferencias con la bancada de Navarro. Sin

\footnotetext{
25 Reza en la exposición de motivos de esta Gaceta lo siguiente: "este documento que presentamos fue suscrito por los doctores Cesar Gaviria Trujillo, en su calidad de presidente de la República, Alfonso López Michelsen, en su condición de director del Partido Liberal, Álvaro Gómez, Antonio Navarro y Horacio Serpa, como presidentes de la Asamblea Nacional Constituyente. Como testigos los doctores Rodrigo Marín Bernal, Carlos Lleras de la Fuente, Otty Patiño y Rosemberg Pabón".
} 
embargo, en el arrancón de las sesiones se zanjaron estas diferencias y parecía que hubo acercamientos. Se trataba de la unión entre curtidos políticos de la vieja guardia contra novatos actores que esperaban realizar cambios de fondo. Esta asociación resultó ser débil y formal, más que de fondo, ya que los verdaderos acercamientos se dieron en la mayoría de los temas con el partido liberal, el partido de Gobierno. En realidad, gran parte de la fragmentada bancada liberal estaba controlada por Ernesto Samper a través de la figura de Serpa. Esto resultaba significativo, pues siempre fueron evidentes los acercamientos políticos personales entre Serpa y Navarro ${ }^{26}$. Ciertamente, el gobierno de Gaviria tuvo plena injerencia en el desarrollo de la Constitución. Esta administración fue hábil al acercarse a la AD, conciliar y proponer estrategias. De suerte que la AD no se rebeló contra el sistema, sino que más bien se insertó en este. No lo hizo a cambio de nada, pues logró imponer temas concretos que, sabía, iban a impactar a la ciudadanía y el electorado. Al final de cuentas prefirió no apostar demasiado, para evitar pérdidas del orden político. No obstante, terminó perdiendo la credibilidad de importantes sectores que tenían más esperanza en un real cambio en las tradiciones políticas del país. Con este propósito, comenta Zalamea: "Asombroso este romperse las vestiduras de los liberales aliados con el M-19. Este movimiento y el liberalismo no solo tienen coincidencias y acuerdos tácitos sino acuerdos ideológicos. Desde el preámbulo, hasta el aplastamiento de la nación” (Zalamea, 1991, p. 109).

Los testimonios sugieren, a modo de conclusión, que la bancada de la AD fue la más disciplinada y cohesionada, sin dejar de ser crítica en muchos aspectos políticos. Ahora bien, el acuerdo de junio de 1991 en la Casa de Nariño minó sin duda alguna la moral y la confianza de algunos constituyentes y simpatizantes de la AD que no compartían la idea de la inhabilidad aprobada por Navarro. Esta idea resultaría ser una apuesta de alto impacto en la que tanto Navarro como la Alianza en su conjunto fueron perdedores. Así concluye Humberto de la Calle en referencia a lo que representó la AD en el marco de la constituyente:

[Navarro] no de otra manera obró en la constituyente. Manejó el suspenso. Planteó la revocatoria, pero fue capaz de hacer una

26 Si bien es un dato anecdótico sin profundidad académica, resulta diciente que Samper haya fungido como padrino de matrimonio de Antonio Navarro a finales de 1994. 
negociación relámpago. Se le tildó de comunista, pero uso un lenguaje moderado. Tenido como archienemigo de los militares, prefirió no tocarlos. Se suponía que iba a arrasar con la propiedad privada y dijo que respetaría el artículo 30 que la protegía (De la Calle, 2008, p.147).

\section{CONGLUSIONES}

Para comienzos de la década de los noventa las fuerzas políticas alternativas, progresistas y de izquierda buscaban un nuevo espacio en un sistema político y electoral ampliamente dominado por los partidos tradicionales. Adicionalmente, la desmovilizada guerrilla del M-19 trataba de cambiar las armas por las urnas y abrazar la vida política. De este modo nacía la AD-M-19 en abril de 1990. En esta nueva organización política confluían diversas organizaciones y realizó rápidamente un golpe de opinión en un mundo en cambio, en un momento de aguda crisis social e institucional para Colombia. Esta crisis terminó saldándose en la aprobación de la redacción de una nueva constitución en 1991.

En ese escenario la AD fue la sensación al obtener 19 curules de las 70 disponibles para dicha asamblea. Si bien este nuevo partido logró atraer una parte importante de votantes, estos resultados fueron relativos, dado que la abstención en las votaciones de diciembre de 1990 superaba el $70 \%$. Esto nos sugiere que el número de votantes fue muy bajo, que hubo un cambio en las preferencias de los ciudadanos. De igual forma, el hecho de que no hubiera un clientelismo en esta votación nos sugiere que se desestimuló a un gran número de votantes. Más allá de esta situación, la AD no supo capitalizar de forma efectiva su participación en la ANC ni proyectarse como organización política a futuro. La lista de constituyentes resultó de una transacción con diversos sectores de la política nacional negociada por Antonio Navarro. Por esta razón, se trató de presentar a la nueva organización como moderada. Sin embargo, esto no era del gusto de muchos sectores al interior de este partido ${ }^{27}$. Así las cosas, la excesiva pluralidad terminó por jugar en contra no solo de la bancada, sino de la misma organización política. Por último, la apuesta de Navarro de aliarse con los sectores liberales, más que con el MSN, desdibujó igualmente su

27 Baste mencionar que hubo tensiones entre los constituyentes Orlando Fals y Carlos Ossa, quienes no ocultaron sus diferencias al interior de la bancada en el marco de las discusiones de la anc. 
visibilidad política; esto se materializó en el acuerdo de la Casa de Nariño de junio de 1991. En el marco de la ANC tanto los partidos tradicionales como los curtidos políticos de la talla de Álvaro Gómez jugaron con la inexperiencia de Navarro y sus seguidores. Así las cosas, la AD perdió la oportunidad de haber sido una bancada más determinante en la redacción de la nueva constitución. A pesar de esto, es indudable que la constitución que hoy nos rige tiene la impronta de un partido que, a pesar de su pronta desaparición, en su momento se consideró la verdadera alternativa política al bipartidismo. Rastrear sus huellas en el sistema político colombiano es necesario académicamente.

\section{REFERENCIAS}

Archivos Fucude. (s.f.). Archivo Alianza Democrática M-19, Cajas1-4

Buenahora, J. (1991). El proceso constituyente. De la propuesta estudiantil a la quiebra del bipartidismo. Pontificia Universidad Javeriana.

Bula, C. (2018). Carlos Pizarro, Bernardo Jaramillo: pensamiento político. Cuellar Editores.

Cabarcas, G. (2011). Militares, política y derecho: sobre los silencios de la constituyente de 1991. Universidad de los Andes.

Cepeda, M. J. (1993). La Constituyente por dentro: mitos y realidades. Presidencia de la República. Consejería para el Desarrollo de la Constitución.

Constaín, J. E. (2019). Álvaro, su vida y su siglo. Random House.

De la Calle, H. (2008). Contra todas las apuestas. Historia intima de la constituyente de 1991. Planeta.

Deas, M. (2019). Barco: vida y sucesos de un presidente crucial y del violento mundo que enfrento. Taurus.

Dugas, J. (Ed.) (1993). La constitución de 1991: ¿un pacto político viable? Universidad de los Andes.

El Tiempo. (1990a, 8 de noviembre) El grupo de Navarro. El Tiempo, 3A

El Tiempo. (1990b, 9 de diciembre). La hora del cambio. El Tiempo, 5A.

Fajardo, J. (2018, 18 de octubre) Entrevista realizada por José David Moreno Mancera. Medellín

Gaceta Constitucional. (1991, 5 de febrero al 25 de septiembre). Gaceta constitucional N. ${ }^{\circ} 1-125$.

Grabe, V. (2017). La paz como revolución: -19. Taller de Edición Rocca.

Gutiérrez, F. (2007). ¿Lo que el viento se llevó? Partidos políticos y democracia en Colombia, 1958-2002. Norma.

Holguín, A. (Ed). (1991). El debate general de la Asamblea Nacional Constituyente. Contraloría General de la República.

Irragori, J. C. (2004). Mi guerra es la paz: Navarro se confiesa. Planeta. 
Misas Arango, G. (2002). La ruptura de los noventa. Del gradualismo al colapso. Universidad Nacional de Colombia.

Pardo, R. (1996). De primera mano. Colombia 1986-1994: entre conflictos y esperanzas. Cerec.

Registraduría Nacional del Estado Civil. (s.f.). Informes estadísticos electorales, Bogotá.

Registraduría Nacional del Estado Civil. (s.f.). Estadísticas electorales, Elecciones a Asamblea Nacional Constituyente, 9 de diciembre de 1990.

Semana. (1990a, 16 de octubre). Las incertidumbres del ministro. Semana.

Semana. (1990b, 28 de octubre). Las cuentas de la constituyente. Semana.

Zalamea, A. (1991). Diario de un constituyente. Temis.

Zuluaga, R. (2008). De la expectativa al desconcierto. El proceso constituyente de 1991 visto por sus protagonistas. Pontificia Universidad Javeriana. 